\title{
Ballooning behavior in the golden orbweb spider Nephila pilipes (Araneae: Nephilidae)
}

\author{
Vanessa M. J. Lee ${ }^{1}$, Matjaž Kuntner ${ }^{2,3,4}$ and Daiqin Li $^{1,2 *}$ \\ Behavioural Ecology and Sociobiology Lab, Department of Biological Sciences, National University of Singapore, Singapore, Singapore \\ ${ }^{2}$ Centre for Behavioural Ecology and Evolution, College of Life Sciences, Hubei University, Wuhan, China \\ ${ }^{3}$ Scientific Research Centre, Institute of Biology, Slovenian Academy of Sciences and Arts, Ljubljana, Slovenia \\ ${ }^{4}$ Department of Entomology, National Museum of Natural History, Smithsonian Institution, Washington, DC, USA
}

\section{Edited by:}

Dina Madeira Da Fonseca, Rutgers,

The State University of New Jersey, USA

\section{Reviewed by:}

Laura J. May-Collado, University of Vermont, USA

Charles James Goodnight,

University of Vermont, USA

Dina Madeira Da Fonseca, Rutgers,

The State University of New Jersey, USA

\section{${ }^{*}$ Correspondence:}

Daiqin Li, Department of Biological

Sciences, National University of

Singapore, 14 Science Drive 4

Singapore 117543, Singapore

e-mail: dbslidq@nus.edu.sg
Ballooning, a mode of aerial dispersal in spiders, is an innate behavior that requires appropriate physiological and meteorological conditions. Although only rarely reported in the golden orbweb spiders, family Nephilidae, the large geographic distributions of most nephilids-in particular of Nephila species-would imply that these spiders likely routinely disperse by ballooning in spite of giant female sizes. Here we study ballooning behavior in the golden orbweb spider Nephila pilipes (Fabricius, 1793). Specifically, we test for the propensity of spiderlings to deploy ballooning as a dispersal mechanism. We subjected a total of 59 first-instar spiderlings to a wind experiment at two wind speeds $\left(2.17 \pm 0.02 \mathrm{~ms}^{-1}\right.$ and $\left.3.17 \pm 0.02 \mathrm{~ms}^{-1}\right)$ under laboratory conditions. Under an average wind speed of $3.17 \mathrm{~ms}^{-1}$, none of the spiderlings exhibited pre-ballooning or ballooning behavior. However, at an average wind speed of $2.17 \mathrm{~ms}^{-1}, 53(89.8 \%)$ spiderlings showed pre-ballooning behavior, and $17(32.1 \%)$ of the pre-ballooners ultimately ballooned. Our results concur with prior reports on spiderlings of other families that pre-ballooning behavior is a requirement for ballooning to occur. Furthermore, although we cannot rule out other dispersal mechanisms such as synanthropic spread, our findings suggest that the widespread $N$. pilipes uses ballooning to colonize remote oceanic islands.

Keywords: aerial dispersal, environmental condition, dispersal mechanism, spiderling, island colonization

\section{INTRODUCTION}

Airborne travel, or ballooning, is a common mode of dispersal in caterpillars, mites, and spiders (Bell et al., 2005). Ballooners are organisms that are attached to a line of any material such as silk, which exploit meteorological conditions and innate behaviors that combined allow drag-induced lift and thus enable the body to become airborne (Bell et al., 2005). Ballooning enables colonization of remote islands and thus plays a prominent role in dispersal biogeography (McCook, 1878; Suter, 1999; Kuntner and Agnarsson, 2011; Agnarsson et al., 2014). Ballooning is well documented in many families of spiders, particularly in Linyphiidae (reviewed in Bell et al., 2005). Much research concerns which spiders disperse by ballooning (Greenstone et al., 1987; Duffey, 1997), how ballooning works (Eberhard, 1987; Reynolds et al., 2006), how it varies between taxa (Richter, 1970; Tolbert, 1977; Greenstone, 1982; Schneider et al., 2001), and what conditions facilitate this behavior (van Wingerden and Vugts, 1979; Greenstone, 1990; Weyman, 1995; Bonte et al., 2003). As a mode of dispersal, ballooning also affects the genetic makeup of populations by increasing gene flow and should be included in models that describe or predict current and future species distributions (Humphrey, 1987; Suter, 1999; Reynolds et al., 2006; Su et al., 2007; Kuntner and Agnarsson, 2011; Năpăruş and Kuntner, 2012; Kuntner et al., 2014).

Beyond the innate ability to balloon, the behavior requires favorable environmental conditions. Meteorological conditions such as air speed, presence of uplifting wind, humidity and temperature are among the factors affecting ballooning (Richter, 1970; Bishop, 1990). Vugts and van Wingerden (1976) showed that wind velocities greater than $3.00 \mathrm{~ms}^{-1}$ reduce the rising air movements and thus decrease the success rate of aerial dispersal in Erigone arctica (White). Ballooning during daylight hours, when wind speed is less than $3 \mathrm{~ms}^{-1}$ is further documented by other studies in E. arctica, Argiope trifasciata (Forskal), A. aurantia (Lucas) and in linyphiids (Vugts and van Wingerden, 1976; Tolbert, 1977; Greenstone, 1982; Suter, 1999). Richter (1970) tested four wolf spiders (Pardosa spp.) for aeronautic behavior in varying temperatures and humidities, and found more ballooning activity in higher temperatures and lower humidity. The above studies thus agree that for the species tested, warm and dry weather facilitates aerial dispersal. More spiders balloon during daytime exploiting convection caused by the sun's heat (Bell et al., 2005).

Individual behavior also affects ballooning, for instance, spiders may seek new suitable habitat when their current one is no longer favorable for their population or survival is overcrowded with conspecifics (Duffey, 1997). Many studies have demonstrated that overcrowding and food shortage can stimulate aerial dispersal, but it remains unclear if other environmental factors can induce this behavior (Duffey, 1997). Spider size additionally determines their ability to balloon (Suter, 1999): only relatively small spiders can 
rely on ballooning for dispersal over long distances (Suter, 1999).

The wind uplift is a pre-requisite for any ballooning behavior (Greenstone, 1982) and ballooning spiders exhibit one of the two types of pre-ballooning behaviors, "tiptoe" position and "rafting" (Bell et al., 2005). The "tiptoe" position involves a spider usually climbing toward an exposed and elevated site (e.g., blade of grass, twig, flower head, or fence post) and emitting silk into rising airstream (Drake and Farrow, 1988; Bishop, 1990; Li and Margolies, 1994). Spiders may increase the length of the silk, or increase the number of strands of silk being released to increase drag force and hence, heighten the chance of traveling further (Bell et al., 2005).

"Rafting" involves anchoring a strand of silk to a post of plant and then paying out silk from the terminal point of the line (Eberhard, 1987). According to Bell et al. (2005), the spiders are already airborne at this moment but still attached to an anchor, seeming to ride the air on a raft, usually on a horizontal plane. Spiders rotate and may release one or more unanchored silk into the air, waiting for the right time to take the uplift of wind and balloon (Tolbert, 1977; Coyle, 1983; Decae, 1987; Bell et al., 2005). Spiderlings of some species are capable of dropping and dangling from a plant on its dragline, where the spiderlings swing in the wind from a slowly lengthening thread, followed by the breaking of the thread and ballooning (Barth et al., 1991).

For decades, researchers have attempted to explain vast geographic distributions of the golden orb weavers, genus Nephila Leach, 1815, and mechanisms the spiders use to colonize remote oceanic islands (Dahl, 1911; Harvey et al., 2007; Su et al., 2007, 2011; Kuntner and Agnarsson, 2011; Kuntner et al., 2013; Agnarsson et al., 2014). Golden orb weavers have often been described as excellent dispersers (Kuntner and Agnarsson, 2011), being abundant and conspicuous representatives of pan-tropical terrestrial invertebrate faunas (Kuntner et al., 2008). Nephila spp. are the largest orb web spiders (Kuntner and Coddington, 2009), and have been recorded on most islands except on the most remote ones such as Hawaii and Polynesia (Kuntner and Agnarsson, 2011). For instance, Nephila populations are found on all the islands of the western Indian Ocean: Madagascar, the Comoro chain, Aldabra and Seychelles, the Mascarene archipelago, and Socotra (Kuntner, 2005b). The Indian Ocean island Nephila inaurata populations are separated from the conspecifics on mainland Africa by the Mozambique Channel over $500 \mathrm{~km}$ wide. Nephila therefore is presumed to have the means of long range dispersal (Kuntner and Agnarsson, 2011), yet it is unclear how these spiders known for gigantic females may achieve this, and the review by Bell et al. does not account for Nephila ballooning.

There is further circumstantial evidence for aerial dispersal in other Nephila species. In an experimental zoogeographical study of islands in Florida Bay, researchers monitored the colonization of terrestrial arthropods at frequent intervals for a year after removal of the original fauna (Simberloff and Wilson, 1969). These authors found that by 250 days after defaunation, the faunas of all islands except for the furthest one regained species numbers and composition similar to those of untreated islands. Nephila clavipes (Linnæus, 1767) was among reappearing species, and aerial transport was postulated (Simberloff and Wilson, 1969).

Among nephilids, and perhaps among orb web spiders as a whole, the biogeography of $N$. pilipes (Figure 1) is extreme, as the species occupies vast areas stretching west-east from India to Solomons and north-south from Japan to Australia (Kuntner, 2005a; Harvey et al., 2007; Su et al., 2007). There is currently no empirical evidence of ballooning in nephilid spiders. But how do they colonize remote islands? One potential mechanism that could allow $N$. pilipes to have such a wide distribution would be the spiders of this species deploying ballooning as their dispersal mechanism during early postembryonic development. Here, we provide the first laboratory experimental evidence of ballooning behavior as means of dispersal in N. pilipes.

\section{MATERIALS AND METHODS \\ COLLECTION AND MAINTENANCE OF SPIDERS}

Adult $N$. pilipes females $(N=36)$ and males $(N=8)$ (Figure 1) were collected in Pulau Ubin, Singapore $\left(1.404371^{\circ} \mathrm{N}\right.$, $103.969148^{\circ} \mathrm{E} ; \quad 1.40864^{\circ} \mathrm{N}, \quad 103.970575^{\circ} \mathrm{E} ; \quad 1.405503^{\circ} \mathrm{N}$, $103.969481^{\circ} \mathrm{E} ; \quad 1.409927^{\circ} \mathrm{N}, \quad 103.967056^{\circ} \mathrm{E}$ ) from August
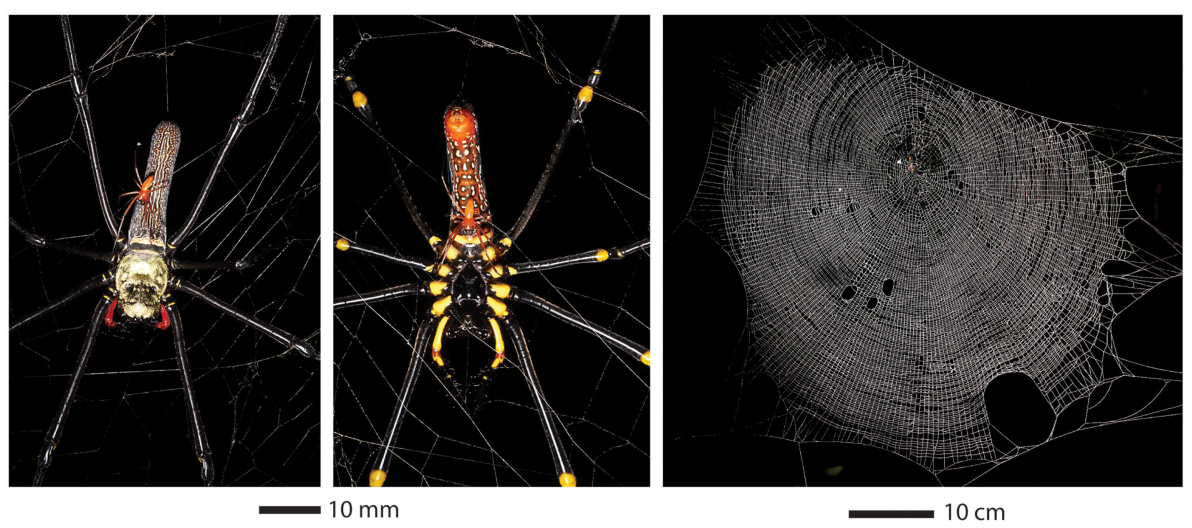

FIGURE 1 | The golden orb weaver, Nephila pilipes, small male on large female (left image, dorsal view; center image, ventral view) and its aerial web (right image). The web image is of a fifth instar juvenile, but the scale is according to the measured web size of the female web in left images. 
2013 to December 2013 and brought to the laboratory. Females were kept individually in large glass cages (length $\times$ width $\times$ height: $30 \times 30 \times 30 \mathrm{~cm}$ ), whereas males were kept individually in small plastic containers (diameter $\times$ height: $4.5 \times 6 \mathrm{~cm}$ ). They were housed in the laboratory with controlled environmental conditions (temperature: $25 \pm 1^{\circ} \mathrm{C}$; relative humidity: $80 \pm 5 \%$; light regime: $12 \mathrm{~L}$ : $12 \mathrm{D}$; light on $0800 \mathrm{~h}$ and off $2000 \mathrm{~h}$ ). Females were fed with two mealworms Tenebrio molitor (Linnæus, 1758) once a week and monitored until they laid eggs and the eggs hatched. A total of 20 spiderlings from each of three eggsacs produced by three females were then transferred and kept in individual jars (diameter $\times$ height $=6.5 \times 9.5 \mathrm{~cm}$ ) and fed five fruit flies Drosophila melanogaster (Meigen, 1830) once a week.

\section{THE WIND EXPERIMENT}

A stage (length $\times$ width $\times$ height: $32.5 \times 22.5 \times 23.5 \mathrm{~cm}$ ) handmade from a paper box with open top was used in the wind experiment. A hole (diameter $=6 \mathrm{~cm}$; center of hole to base $=$ $11.5 \mathrm{~cm}$; center of hole to left side of box $=10.5 \mathrm{~cm}$; center of hole to right side of box $=11.5 \mathrm{~cm}$ ) was cut out on the side to allow space for the fan to ensure that the wind was directed toward the experimental stage and not dissipated. Although it might limit the wind flow, it only limited the wind flow partially. Black paper was used as background within the box, to increase contrasts for clearer observations of the spiderlings and their silk. A plantlet was placed in the set-up to serve as a platform for the tested spiderling. Airflow was allowed in and out of the set-up to facilitate ballooning conditions.

The wind experiment was carried out in an experimental room with controlled environmental conditions (temperature: $25 \pm 1{ }^{\circ} \mathrm{C}$; relative humidity: $80 \pm 5 \%$ ) under a white fluorescent light between 0900 and $1700 \mathrm{~h}$. We assured that no silk from the spiderling was attached to any parts of the experimental set-up. Once a spiderling was spotted to initiate a bridging behavior, that is, emitting silk-lines which attached to the interior of the experimental box or to any structure within the reach of the spiderling, the bridging silk was removed to ensure that the spiderling did not display bridging behavior, and the spiderling was repositioned on the plantlet. The trial began when a spiderling was placed on a plant and exposed to wind from a mini table electric fan (Lileng ${ }^{\mathrm{TM}}-826$, Lileng, China) for $5 \mathrm{~min}$. Each spiderling was given two trials, one under an average wind speed of $2.17 \pm 0.02 \mathrm{~ms}^{-1}$ and the other under a wind speed of $3.17 \pm 0.02 \mathrm{~ms}^{-1}$, with $5 \mathrm{~min}$ per trial to observe for any ballooning behavior, and $5 \mathrm{~min}$ between two trials. All trials were documented using a Powershot SX50 HS digital camera (Canon, Japan). A spiderling was defined to be exhibiting pre-ballooning behavior if it showed any sign of rafting or tiptoeing behavior. Once an individual exhibited ballooning behavior, it was deemed as capable of ballooning. A spiderling was verified to have shown ballooning behavior only when it was not attached to any of the plant parts or to the interior of the experimental set-up and observed to be floating in the experimental box. A total of 59 first-instar spiderlings were tested, never more than once with the same wind speed. We performed a total of 118 trials.
Wind speeds were measured using Extech ${ }^{\circledR}$ Instruments (USA) HD350: Heavy Duty Pitot Tube Anemometer and Differential Pressure Manometer. The wind speed was obtained by placing a probe that is sensitive to the pressure of the wind generated from the electric fan. Points were taken at the center of the fan and twice on each side of the fan, to calculate the average wind speed.

\section{RESULTS}

All tested spiderlings were of the first post-hatching instar (mean \pm SE body length: $1.2 \pm 0.1 \mathrm{~mm}$; mean \pm SE mass: $0.21 \pm$ $0.01 \mathrm{mg}$ ). Under an average wind speed of $3.17 \pm 0.02 \mathrm{~ms}^{-1}$, none of the spiderlings exhibited pre-ballooning or ballooning behavior. However, of the 59 spiderlings tested, 53 (89.8\%) were observed to show pre-ballooning behavior (Figure 2) under an average wind speed of $2.17 \pm 0.02 \mathrm{~ms}^{-1}$. Spiderlings that exhibited pre-ballooning behavior spun silk, extended down from a high point of the plantlet, and hung and swung in the airflow. This observed behavior resembled rafting, whereby the spiderlings hung down from the plantlet and swung along in the wind directions till there was sufficient uplift of wind, allowing them to balloon. Of the 53 pre-ballooning spiderlings, 17 (32.1\%) subsequently ballooned (Figure 2), while those spiderlings that never pre-ballooned also never ballooned. Thus, $28.8 \%$ of all spiderlings exhibited ballooning behavior (Figure 2).

\section{DISCUSSION}

This study provides the first empirical evidence that the firstinstar $N$. pilipes spiderlings are capable of, and perform ballooning in the laboratory set-up, suggesting ballooning as a possible means of long distance dispersal of $N$. pilipes and more generally, of Nephila species. Pre-ballooning seems to be a prerequisite for ballooning behavior in $N$. pilipes. In our study, all the spiderlings that were observed to balloon had also exhibited pre-ballooning behavior, while none of the spiderlings that had failed to pre-balloon subsequently ballooned under the wind speed less than $3 \mathrm{~ms}^{-1}$. Studies on other spiders have suggested

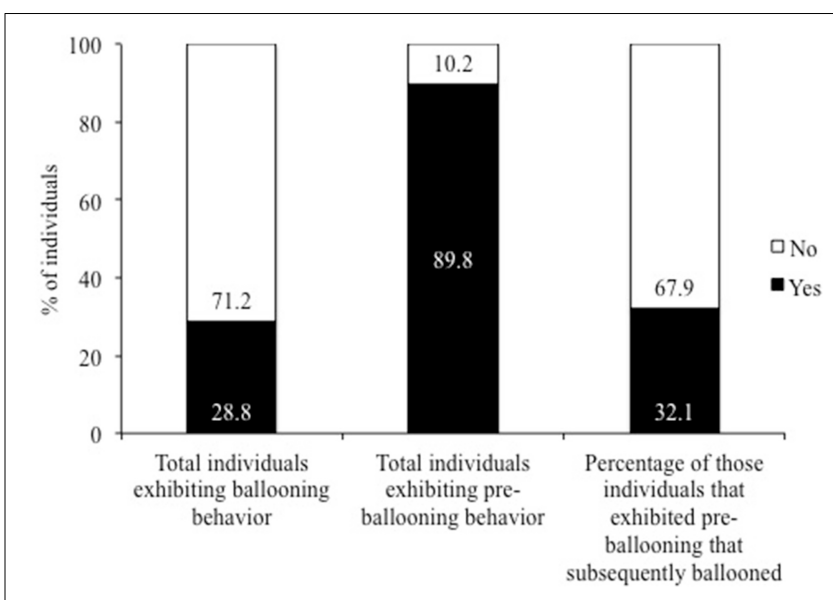

FIGURE 2 | Percentages of spiderlings exhibiting ballooning behavior, pre-ballooning behavior and pre-ballooners that proceeded on to ballooning. 
that pre-ballooning behavior precedes ballooning and is a reliable indication of an aerial dispersal capacity (Richter, 1970; Schneider et al., 2001).

The $28.8 \%$ of the $N$. pilipes spiderlings exhibiting ballooning behavior is a considerably lower percentage compared to studies on other species (Richter, 1970; Greenstone, 1982; Greenstone et al., 1987; Henschel et al., 1995; Schneider et al., 2001). For example, in the study of Greenstone et al. (1987) 69 and 98.5\% of linyphiid and araneid spiderlings ballooned, respectively. The lower percentage in Nephila may reflect real differences between various orbweb spider clades, but it could plausibly also be due to different study conditions. For example, spiders in the previous studies may have been starved or kept in overpopulated areas (Richter, 1970; Greenstone, 1982; Greenstone et al., 1987; Henschel et al., 1995; Duffey, 1997; Schneider et al., 2001), and spiders may be more likely to attempt ballooning under stressful conditions. In our study, the spiderlings were in non-stressful condition, as they were well fed and the rearing density was limited to 20 individuals per jar (diameter $\times$ height $=6.5 \times 9.5 \mathrm{~cm}$ ). We also tested spiderlings individually, with only the wind and room temperature as variables, thus eliminating any possibilities of group-induced effect on ballooning behavior. On the other hand, Richter (1970) reported experimental groups of 20 spiderlings, potentially risking unwanted group-induced effects on ballooning behavior. As ballooning may be seen as means to improve habitat conditions in unstable environments (Boer, 1990), prior studies may have overestimated ballooning spider percentages in stable environments, more so than our study with relatively low percentage of ballooners.

Ballooning behavior is commonly observed in small spiderlings of numerous spider species (Greenstone et al., 1987). Most ballooners observed in the study by Greenstone et al. (1987) weighted $1.0 \mathrm{mg}$ or less, agreeing with our findings on $N$. pilipes where spiderlings of comparable mass (mean $=0.21 \mathrm{mg}$ ) showed ballooning behavior. Other studies have pointed out (Richter, 1970; Turnbull, 1973; Salmon and Horner, 1977; Dean and Sterling, 1985; Decae, 1987) that size may be one of the key limiting factors of ballooning in spiders, and this must be particularly relevant for Nephila that is known for gigantic and heavy females (Kuntner et al., 2012).

As in previous studies (Barth et al., 1991; Weyman, 1995; Duffey, 1997), our study found that not all spiderlings that exhibit pre-ballooning behavior will eventually balloon. In N. pilipes, although $89.8 \%$ of 59 spiderlings exhibited pre-ballooning behavior, only $32.1 \%$ of the pre-ballooners eventually ballooned. There may be other factors that prevent the spiderlings from ballooning. Given the prolonged presence of the right conditions (e.g., wind speed, suitability of the current habitat, humidity, or temperature) for the individuals to react, pre-ballooning could eventually lead to ballooning. In the experiments, each spiderling was only given $5 \mathrm{~min}$ per trial. In the wild, the conditions that favor ballooning may happen at a longer time frame with various other factors coming into play, and thus, enable individuals to disperse by ballooning. In addition, not all the spiderlings are expected to disperse (balloon) from the source population. The actual ballooning rate of spiders may furthermore strongly depend on ecological conditions. For example, there was a significant decline in numbers of ballooning linyphiids during climate change (the increase in temperature, mean wind speed and percentage of days with mean wind speed $>3 \mathrm{~ms}^{-1}$ ) between 1973 and 2000 (Thomas et al., 2006).

Wind speeds exceeding $3.00 \mathrm{~ms}^{-1}$ impede rising air movements and are therefore poor ballooning conditions (Vugts and van Wingerden, 1976; Tolbert, 1977; Greenstone, 1982; Suter, 1999). Our study on $N$. pilipes corroborates that a combination of parameters is needed for spider ballooning to occur (Richter, 1970), including wind speeds of less than $3 \mathrm{~ms}^{-1}$, sufficient airflow in the environment and the right physiological state of the spider. Specific details of the ballooning mechanism such as how the silk for ballooning is released and in what quantities, need further investigation. In this study, the spiderlings were only observed to be "rafting" from a high end of the plantlet, waiting for the right time to balloon. Future work could also assess better what the driving factors for this behavior are, in addition to the favorable speed of wind and meteorological conditions in the laboratory. In addition, we also note that ballooning studies would ideally include a control organism (a non-ballooner). However, in our case we focused on a single species because prior ballooning research has been too preliminary to conclusively establish non-ballooners; there is a lack of experimental research that would allow comparisons of ballooning abilities across orb-weaving species.

Showing that ballooning is a likely means of aerial dispersal in $N$. pilipes, we suggest that ballooning may also be widespread in other Nephila species and other nephilids, as has been repeatedly suggested in the literature (Simberloff and Wilson, 1969; Kuntner and Agnarsson, 2011). Results from our study suggest that aerial transport is not only possible, but likely in early developmental stages in Nephila despite their large adult sizes. However, considering that orb-weaving species including certain nephilids (e.g., Nephilingis cruentata) are often associated with humans (Kuntner, 2007), another possibility that would explain their wide distributions is synanthropic transport of spiders or their eggs to new areas. Having the propensity to balloon does not necessary rule out the possibility of $N$. pilipes to undergo human-mediated dispersal. Ballooning may only be a mechanism for spiderlings to disperse locally, not necessarily at long-ranges. Future research may focus on the relative importance of ballooning, particularly at long ranges, compared with other means of transport in Nephila and other spiders.

\section{ACKNOWLEDGMENTS}

We thank William H. Piel for providing crucial feedback on the first draft and Cui Yong Dong for lending the resources from National University of Singapore (NUS) T-Lab to make this research project possible. The project was partially supported by the grants from MOE AcRF Tier 1 to Daiqin Li (R-154-000-591112) and from NSFC (30770332), and by the Slovenian Research Agency grant P1-10236 to Matjaž Kuntner.

\section{REFERENCES}

Agnarsson, I., Cheng, R.-C., and Kuntner, M. (2014). A multi-clade test supports the intermediate dispersal model of biogeography. PLOS ONE 9:e86780. doi: 10.1371/journal.pone.0086780 
Barth, F. G., Komarek, S., Humphrey, J. A. C., and Treidler, B. (1991). Drop and swing dispersal behavior of a tropical wandering spider: experiments and numerical model. J. Comp. Physiol. A 169, 313-322. doi: 10.1007/BF00206995

Bell, J. R., Bohan, D. A., Shaw, E. M., and Weyman, G. S. (2005). Ballooning dispersal using silk: world fauna, phylogenies, genetics and models. Bull. Entomol. Res. 95, 69-114. doi: 10.1079/BER2004350

Bishop, L. (1990). Meteorological aspects of spider ballooning. Environ. Entomol. 19, 1381-1387.

Boer, P. J. D. (1990). The survival value of dispersal in terrestrial arthropods. Biol. Conserv. 54, 175-192. doi: 10.1016/0006-3207(90)90050-Y

Bonte, D., Vandenbroecke, N., Lens, L., and Maelfait, J. P. (2003). Low propensity for aerial dispersal in specialist spiders from fragmented landscapes. Proc. R. Soc. Lond. B 270, 1601-1607. doi: 10.1098/rspb.2003.2432

Coyle, F. A. (1983). Aerial dispersal by mygalomorph spiderlings (Araneae, Mygalomorphae). J. Arachnol. 11, 283-286.

Dahl, H. (1911). Die Verbreitung der Spinnen spricht gegen ein frühere Landverbindung der Südspitzen unsrer Kontinente. Zool. Anz. 37, 270-282.

Dean, D. A., and Sterling, W. L. (1985). Size and phenology of ballooning spiders at two locations in Eastern Texas. J. Arachnol. 13, 111-120.

Decae, A. E. (1987). "Dispersal: ballooning and other mechanism," in Ecophysiology of Spiders, ed W. Nentwig (Berlin; Heidelberg: Springer), 348-356. doi: 10.1007/978-3-642-71552-5 26

Drake, V. A., and Farrow, R. A. (1988). The influence of atmospheric structure and motions on insect migration. Ann. Rev. Entomol. 33, 183-210. doi: 10.1146/annurev.en.33.010188.001151

Duffey, E. (1997). "Aerial dispersal in spiders," in Proceedings of the 17th European Colloquium of Arachnology (Edinburgh), 187-192.

Eberhard, W. G. (1987). How spiders initiate airborne lines. J. Arachnol. 15, 1-9.

Greenstone, M. H. (1982). Ballooning frequency and habitat predictability in two wolf spider species (Lycosidae: Pardosa). Fla. Entomol. 65, 83-89. doi: $10.2307 / 3494147$

Greenstone, M. H. (1990). Meteorological determinants of spider ballooning: the roles of thermals vs. the vertical windspeed gradient in becoming airborne. Oecologia 84, 164-168. doi: 10.1007/BF00318267

Greenstone, M. H., Morgan, C. E., and Hultsch, A.-L. (1987). Ballooning spiders in Missouri, USA, and New South Wales, Australia: family and mass distributions. J. Arachnol. 15, 163-170.

Harvey, M. S., Austin, A. D., and Adams, M. (2007). The systematics and biology of the spider genus Nephila (Araneae: Nephilidae) in the Australasian region. Inverteb. Syst. 21, 407-451. doi: 10.1071/IS05016

Henschel, J. R., Schneider, J., and Lubin, Y. D. (1995). Dispersal mechanisms of Stegodyphus (Eresidae): do they balloon? J. Arachnol. 23, 202-204.

Humphrey, J. A. C. (1987). Fluid mechanic constraints on spider ballooning. Oecologia 73, 469-477. doi: 10.1007/BF00385267

Kuntner, M. (2005a). A revision of Herennia (Araneae: Nephilidae: Nephilinae), the Australasian 'coin spiders'. Inverteb. Syst. 19, 391-436. doi: 10.1071/IS05024

Kuntner, M. (2005b). Systematics and Evolution of Nephilid Spiders (Araneae Nephilidae New Rank). Ph.D. thesis, George Washington University.

Kuntner, M. (2007). A monograph of Nephilengys, the pantropical "hermit spiders" (Araneae, Nephilidae, Nephilinae). Syst. Entomol. 32, 95-135. doi: 10.1111/j.1365-3113.2006.00348.x

Kuntner, M., and Agnarsson, I. (2011). Phylogeny of a successful aerial disperser: the golden orb spder Nephila on Indian Ocean islands. BMC Evol. Biol. 11:119. doi: 10.1186/1471-2148-11-119

Kuntner, M., Arnedo, M. A., Trontelj, P., Lokovšek, T., and Agnarsson, I. (2013). A molecular phylogeny of nephilid spiders: evolutionary history of a model lineage. Mol. Phylogenet. Evol. 69, 961-979. doi: 10.1016/j.ympev.2013.06.008

Kuntner, M., and Coddington, J. A. (2009). Discovery of the largest orbweaving spider species: the evolution of gigantism in Nephila. PLoS ONE 4:e7516. doi: 10.1371/journal.pone.0007516

Kuntner, M., Coddington, J. A., and Hormiga, G. (2008). Phylogeny of extant nephilid orbweaving spiders (Araneae, Nephilidae): testing morphological and ethological homologies. Cladistics 24, 147-217. doi: 10.1111/j.10960031.2007.00176.x

Kuntner, M., Năpăruș, M., Li, D., and Coddington, J. A. (2014). Phylogeny predicts future habitat shifts due to climate change. PLOS ONE 9:e98907. doi: 10.1371/journal.pone.0098907
Kuntner, M., Zhang, S., Gregoriè, M., and Li, D. (2012). Nephila female gigantism attained through post-maturity molting. J. Arachnol. 40, 345-347. doi: 10.1636/B12-03.1

Li, J., and Margolies, D. C. (1994). Barometric pressure influences initiation of aerial dispersal in the twospotted spider mite. J. Kansas Entomol. Soc. 67, 386-393.

McCook, H. C. (1878). Supplementary note on the aeronautic flight of spiders. Proc. Acad. Nat. Sci. Philad. 1878, 337-339.

Năpăruş, M., and Kuntner, M. (2012). A GIS model predicting potential distributions of a lineage: a test case on hermit spiders (Nephilidae: Nephilengys). PLoS ONE 7:e30047. doi: 10.1371/journal.pone.0030047

Reynolds, A. M., Bohan, D. A., and Bell, J. R. (2006). Ballooning dispersal in arthropod taxa: conditions at take-off. Biol. Lett. 3, 237-240. doi: 10.1098/rsbl.2007.0109

Richter, C. J. J. (1970). Aerial dispersal in relation to habitat in eight wolfspider species (Pardosa, Araneae, Lycosidae). Oecologia 5, 200-214. doi: 10.1007/BF00344884

Salmon, J. T., and Horner, N. V. (1977). Aerial dispersion of spiders in North Central Texas. J. Arachnol. 5, 153-157.

Schneider, J. M., Roos, J., Lubin, Y., and Henschel, J. R. (2001). Dispersal of Stegodyphus dumicola (Araneae, Eresidae): they do balloon after all! J. Arachnol. 29, 114-116. doi: 10.1636/01618202(2001)029[0114:DOSDAE]2.0.CO;2

Simberloff, D. S., and Wilson, E. O. (1969). Experimental zoogeography of islands: the colonization of empty islands. Ecology 50, 278-296. doi: 10.2307/1934856

Su, Y.-C., Chang, Y.-H., Lee, S.-C., and Tso, I.-M. (2007). Phylogeography of the giant wood spider (Nephila Pilipes, Araneae) from Asian-Australian regions. J. Biogeogr. 34, 177-191. doi: 10.1111/j.1365-2699.2006.01617.x

Su, Y.-C., Chang, Y.-H., Smith, D., Zhu, M.-S., Kuntner, M., and Tso, I.-M. (2011) Biogeography and speciation patterns of the golden orb spider genus Nephila (Araneae: Nephilidae) in Asia. Zool. Sci. 28, 47-55. doi: 10.2108/zsj.28.47

Suter, R. B. (1999). An aerial lottery: the physics of ballooning in a chaotic atmosphere. J. Arachnol. 27, 281-293.

Thomas, C., Brooks, S., Goodacre, S., Hewitt, G., Hutchings, L., and Woolley, C. (2006). Aerial Dispersal by Linyphiid Spiders in Relation to Meteorological Parameters and Climate Change. Avaliable online at: http://www.statslab.cam.ac.uk/ leah/stevepapers/thobghhw06.pdf

Tolbert, W. W. (1977). Aerial dispersal behavior of two orb weaving spiders. Psyche 84, 13-27. doi: 10.1155/1977/52152

Turnbull, A. L. (1973). Ecology of the true spiders (Araneomorphae). Ann. Rev. Entomol. 18, 305-348. doi: 10.1146/annurev.en.18.010173.001513

van Wingerden, W. K. R. E., and Vugts, H. F. (1979). "Ecological and meteorological aspects of aeronautic dispersal of spiders," in Proceedings 1st International Conference on Aerobiology. Berichte Umweltbundesamt 5/79, (Berlin: Erich Schmid Verlag), 212-219.

Vugts, H. F., and van Wingerden, W. K. R. E. (1976). Meteorological aspects of aeronautic behaviour of spiders. Oikos 27, 433-444. doi: $10.2307 / 3543462$

Weyman, G. S. (1995). Laboratory studies of the factors stimulating ballooning behavior by linyphiid spiders (Araneae, Linyphiidae). J. Arachnol. 23, 75-84.

Conflict of Interest Statement: The authors declare that the research was conducted in the absence of any commercial or financial relationships that could be construed as a potential conflict of interest.

Received: 06 October 2014; accepted: 03 January 2015; published online: 21 January 2015.

Citation: Lee VMJ, Kuntner M and Li D (2015) Ballooning behavior in the golden orbweb spider Nephila pilipes (Araneae: Nephilidae). Front. Ecol. Evol. 3:2. doi: 10.3389/ fevo.2015.00002

This article was submitted to Behavioral and Evolutionary Ecology, a section of the journal Frontiers in Ecology and Evolution.

Copyright (C) 2015 Lee, Kuntner and Li. This is an open-access article distributed under the terms of the Creative Commons Attribution License (CC BY). The use, distribution or reproduction in other forums is permitted, provided the original author(s) or licensor are credited and that the original publication in this journal is cited, in accordance with accepted academic practice. No use, distribution or reproduction is permitted which does not comply with these terms. 